\title{
CYCLIC OCULOMOTOR PALSY
}

\author{
BY
}

\section{IAN S. McGREGOR}

\author{
Ophthalmic Surgeon, Glasgow Royal Infirmary
}

THERE have been described about thirty cases of this interesting phenomenon. Axenfeld and Schürenberg (1901) have their names attached to the condition in the Continental literature; they called it " Cyclic Congenital Oculomotor Disease". Fuchs, however, described a case much earlier (1893). The clinical picture is quite different from recurrent oculomotor palsy. The cause is still a matter of conjecture as no case has been examined post-mortem.

Essentially the clinical picture is a rhythmic, or cyclic palsy of the muscles moving the eye and usually also of the levator muscle of the upper lid associated with dilatation of the pupil during the stage of full paresis and ptosis, and contraction of the pupil as the lid rises and the muscles of the globe recover part of their power. The condition is unilateral and may be acquired, or congenital. The movements are quite involuntary and the rhythmic alteration of tone in the paralysed muscles goes on during sleep and waking. When there is intermittent ptosis the condition is quite striking. The fourth and sixth nerves are much less commonly paralysed than the third, or part of the third, nerve. When the ptosis is absent and the extraocular muscle palsy is slight the pupil only may show the rhythmic movement. The mild cases of cyclic oculomotor palsy without ptosis may therefore be readily overlooked.

\section{Case History}

C.H. aged eight years. Spontaneous delivery. The right eyelid has appeared abnormal since birth. There is almost a complete ptosis, but every few minutes throughout the day and night the right eye opens involuntarily to a normal extent for a period of about thirty seconds. This movement is quite involuntary and cannot be influenced in any way by the child's own action. On timing the active (lid raised) and passive (ptosed lid) stages over fifteen minutes, the average interval between active stages is one-and-a-half minutes and the lid remains up for thirty seconds. The longest interval between phases was two minutes, and the shortest, one minute. In the ptosed or passive stage the palpebral fissure is three mms. wide (Fig. 3) and it rises in jerks until the fissure is of normal width (Fig. 2). The mother states that when the child is sitting quiet the lid does not rise so often. Sometimes the lid does not rise so completely. Voluntary movement of the eyes did not seem to influence the rate of lid rising. Prostigmine had no effect.

There is a divergent squint of the right eye, the corneal margin being one $\mathrm{mm}$. from the outer canthus as can be seen in Fig. 1. There is a slight adduction of the globe during the active, or lid raised stage as can be seen in Fig. 2. There is no voluntary vertical movement of the right eye, and no downward movement on adduction. The only voluntary movement is slight abduction.

Fig. 3 shows the passive stage of ptosis. The pupil during the passive stage is dilated in the right eye- diameter four mms. (Fig. 1) and reacts very poorly to light and accommodation, and to pain and lid closure stimuli. It is regular. During the active phase the pupil becomes equal to the normal fellow pupil and reacts

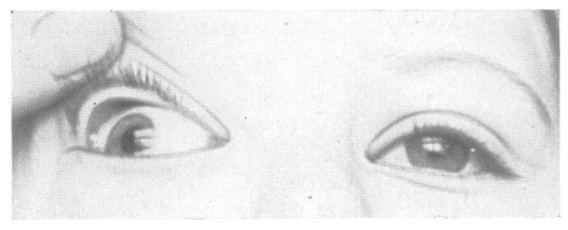

FIG. 1.

normally to light and accommodation. The refraction in the passive stage in the right eye is $\frac{+0 \cdot 50}{-1 \cdot 00 / 180^{\circ}}$ and this becomes $\frac{-0.50}{-1.50 / 180^{\circ}}$ when the lid rises. With $-1 \cdot 50 / 180^{\circ}$, vision is improved in the right eye from

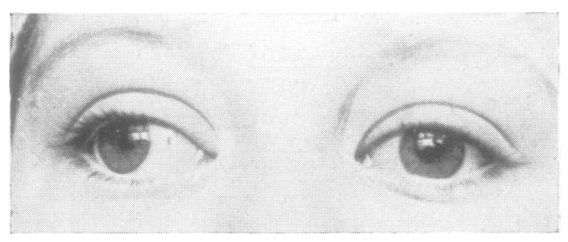

FIG. 2.

$6 / 36$ to $6 / 18$ Snellen. Vision in the left eye is $6 / 9$ Snellen, there being a small error of hypermetropic astigmatism. Cocaine 2 per cent. dilates the pupil widely as does also. Homatropine 1 per cent.; Eserine $\frac{1}{2}$ per cent. and

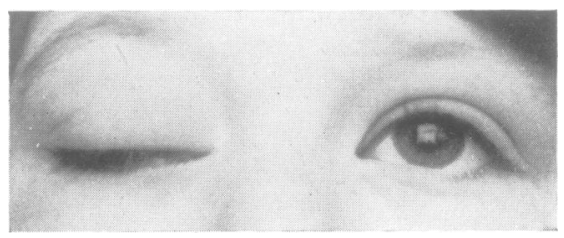

FIG. 3.

Pilocarpin 2 per cent. produce contraction of the pupil. Examination with the corneal microscope reveals no structural abnormality in the anterior segment of the eye. No other neurological abnormality was found. Stereoscopic X-ray examination of the skull revealed a thickening of the right sphenoidal ridge and this was reported to be of congenital origin. The child looks healthy and is well grown for her age and the Wasserman reaction is negative. The family history is negative and the child has had no serious illness.

\section{Discussion}

The clinical picture of these rare palsies varies somewhat in the literature of the thirty cases reported. Any oculomotor nerve may be involved, or 
any branch. The lid paralysis occurred in twothirds of the cases. The internal rectus is very commonly involved and the superior oblique, rather uncommonly. There is rarely involvement of other cranial nerves, the fifth, seventh, and ninth. Only one bilateral case is described and the lids were involved alternately, one eye being in the active phase, while the other was in the palsied, or passive phase. The sixth nerve usually escapes. Contraction of the dilated pupil during the active phase is a constant feature with or without activity of the internal rectus. Occasionally there is nystagmus in one, or both eyes. Nearly all cases show amblyopia of some degree in the affected eye. The classical description of Axenfeld and Schürenberg has had to be modified as more cases came to be reported and it was seen that the condition need not be congenital. Greeves (1913) reported a case in a girl aged, seven years, after measles. Salus (1912) described a case aged five years with suppurating submaxillary glands which required operation, the condition of unilateral cyclic oculomotor palsy supervening thereafter. At the age of twenty years this patient still had intermittent discharge from these glands. Bielschowsky (1929), who described four cases out of a series of 1,700 cases of ocular palsy, showed that the intermittent or cyclic character of the palsy may occur some time after the onset of palsy. Later Bielschowsky (1935) collected the reports of thirty-two cases of cyclic oculomotor paralysis and of these he had seen ten cases himself. He was convinced that there were slight or rudimentary instances of the phenomenon and that if such cases were included that the condition would be found not to be quite so rare as is supposed. The alternate contraction and dilatation of the pupil is the only feature common to all the cases described. There is great variation in the degree of paralysis of the extraocular muscles and levator palpebral muscle on the affected side. No one extraocular muscle is constantly implicated in the palsy, though one or more supplied by the third nerve are usually involved. In one-third of the cases Bielschowsky says the upper lid is not involved and there is no intermittent ptosis. The elevator and depressor muscles of the eyeball never participate in alternating spasm and relaxation. Mild cases therefore may show only the phenomenon of alternating relaxation and contraction of the apparently paretic pupil with slight paralysis of one or more of the extraocular muscles or the levator muscle of the lid. As such they may be missed or reported as a peculiar pupil-phenomenon with a third nerve palsy. Here the intermittent, or cyclic part of the clinical picture is limited to the pupil movement and Bielschowsky thinks these cases should be included in the group of cyclic oculomotor palsies. In half the cases the condition is acquired in early childhood; the others are congenital. One single case is reported as beginning at the age of seventeen. Bielschowsky attributes the cyclic behaviour of the muscles to varying vasomotor conditions in the region of the third nerve nucleus.
Salus (1912) thought that this cyclic oculomotor palsy was due to aberration of regenerating nerve fibres as is considered to be the cause of " mitbewegung", or, as it is called in this country, "the jaw-winking phenomenon of Marcus Gunn", where the palsied lid rises with the action of the pterygoids. Bielschowsky when speaking of the pseudo Græfe phenomenon thinks that this is due to regenerating fibres from the nucleus finding their way into the wrong paths. The movements of cyclic oculomotor palsy, however, are not initiated by voluntary movement as in the "jaw-winking" and the pseudo Græfe phenomena. The essential feature of cyclic palsy is that it is automatic and rhythmic. Bielschowsky thought that the lesion was in the neighbourhood of the third nucleus and that vasomotor influences produced the rhythmicity. It may be that the blood supply is impaired by disease or injury, or congenital defect and that there is a "storage" as it were of sub-minimal stimuli in the damaged nucleus, which when they become adequate lead to periodic discharge along the spared, or partially spared, paths. The influence of excitement or anxiety in increasing the rate of the cycle might be explained on this vascular basis. When the child was sitting quietly reading the rate of the cycle was less.

In our case there was a thickening of the sphenoidal ridge on that side which was considered probably to be congenital. The child was too young for arteriography. In adults this might prove of value in revealing a possible abnormal blood supply, but it is likely that the solution still awaits the evidences of post-mortem examination.

\section{Summary}

1. A case of cyclic oculomotor palsy as described, of which over thirty cases have appeared in the literature.

2. No report on autopsy has been made in any of these cases.

3. The interest of this oculomotor palsy lies in its cyclic, or rhythmic and automatic character.

The explanations are necessarily conjectural, but it seems possible that damage has occurred to the nucleus, or its efferent paths congenitally, or as a result of disease. There may be some "storage " of sub-threshold stimuli in the remaining effective part of the nucleus and these stimuli when they reach adequate intensity, overflow periodically to produce the lid rising and associated changes of the active phase of the cycle.

\section{REFERENCES}

Axenfeld, T., and Schürenberg, E. (1901). Klin. Mbl. Augenheilk, 39, 64.

Bielschowsky, A. (1903). Ibid., 40, 308.

(1929). Grafes Arch. Ophthal., 121, 659.

(1935). Lectures on Motor Anomalies of the Eyes, Reprinted from Arch. Ophthal. Amer. med. Ass. Chicago, 1944, p. 35.

Fuchs, E. (1893). Beitr. Augenheilk, 11, 12.

Greeves, R. (1913). Proc. roy. Soc. Med., 6, Sect. Ophthal., 23.

Salus, R. (1912). Klin. Mbl. Augenheilk., 50, ii 66. 